\title{
Investigating the Impact of Brand Personality Dimensions on Customer Responses
}

\author{
${ }^{1}$ Mohammad Javd Amraei, ${ }^{2}$ Nasrollah Khalili Tirtashi* \\ ${ }^{1,2}$ Department of Management, Naragh Branch, Islamic Azad University, Naragh, Iran
}

\section{Abstract}

Seeks to provide empirical support for the "brand personality effect", that is, the direct influence that brand personality will have on a variety of consumer-driven outcomes. Tests a series of hypotheses using experimental research design with 192 subjects. Support is found for all proposed hypotheses. These findings indicate that brand personality will have a positive influence on product evaluations and that subjects exposed to a brand's personality will have a significantly greater number of brand associations; significantly greater proportion of brand associations; significantly greater unique brand associations; significantly greater proportion of congruent brand associations; and significantly greater proportion of strong brand associations. This paper conceptually establishes brand personality and empirically demonstrates the brand personality effect on consumer-based outcomes. This finding strengthens the brand personality literature and establishes a baseline study for future empirical research. Brand personality has received levels of research from academics and practitioners alike, but this research presents the first empirical test of the direct effect of brand personality and how it drives consumer behavior.

Keywords: Brand personality, Experimental design, Customer responses

\section{Introduction}

Since the concept of brand personality emerged over three decades ago, there has been a burgeoning interest in the subject among marketing academicians and practitioners (Aaker, 1997; Carr, 1996; Duboff, 1986; Durgee, 1988; Kassarjian, 1971; Levy, 1959; Ogilvy, 1988; Plummer, 1985; Sirgy, 1982). For example, consumer researchers have investigated how brand personality encourages self- expression and association (Belk, 1988; Kleine et al., 1993; Malhotra, 1981), and practitioners have speculated about the utility of brand personality in terms of product differentiation (Biel, 1993; Halliday, 1996). While there is general agreement that some brands can have personalities that are associated with positive consequences, evidence of such benefits has been somewhat threadbare. Aaker (1997, p. 347) defines brand personality as "the set of human characteristics associated with a brand." The clear delineation of brand personality, however, remains somewhat vague and indistinguishable from other constructs such as brand image or brand identity. Essentially, little is known about why consumers try to infuse human traits into brands. Further, there is a dearth of research that empirically demonstrates the utility of developing a strong, positive brand personality; that is, what is the effect that brand personality will have on

\section{*Corresponding Author: Nasrollah Khalili Tirtashi}


consumer-related outcomes. While marketing practitioners seem to readily accept the notion that brand personality is related to favorable advantages, support for this assumption is primarily anecdotal and these relationships have not been subjected to extensive empirical testing (see exceptions in Aaker, 1999; Batra et al., 1993; Haigood, 1999).

The purpose of this paper, therefore, is to present empirical evidence of brand personality's effect on different performance outcomes using experimental research. This manuscript is organized as follows. First, we provide a selective review of the branding literature to provide the necessary support for this research. Next, we present a series of hypotheses regarding the relationship of brand personality to important product judgments and other brand-equity- related measures. We then conduct an empirical study to test what we term the "brand personality effect"; that is, the impact that brand personality has on these variables. Finally, we conclude with a discussion of findings in terms of their implications for marketing theory and practice.

\section{Conceptual development}

Recent research on brand personality defines the construct as "the set of human characteristics associated with a brand" and documents a stable set of personality dimensions that are thought to underlie the construct (Aaker, 1997). The brand personality dimension corresponds to the "big five" human personality structure developed by Norman (1963) and includes:

- $\quad$ sincerity, typified by traits such as wholesome, down-to- earth, and honest;

- $\quad$ excitement, typified by traits such as daring, imaginative, and exciting;

- $\quad$ competence, typified by traits such as intelligent, secure, and confident;

- $\quad$ sophistication, typified by traits such as glamorous, smooth, and charming;

- $\quad$ ruggedness, typified traits such as strong, masculine, and western.

Aaker's (1997) brand personality scale (BPS) measures the extent to which a given brand possesses any of these personality traits. Aaker's work has inspired a spate of studies that seek to validate and refine the BPS across a variety of contexts and cultures; however, research in this vein generally diagnoses the nature of a brand's personality - not its impact on brand performance.

Consumer researchers suggest that numerous benefits may accrue to brands with strong, positive brand personalities. A favorable brand personality is thought to increase consumer preference and usage (Sirgy, 1982), increase emotions in consumers (Biel, 1993), increase levels of trust and loyalty (Fournier, 1998), encourage active processing on the part of the consumer (Biel, 1992), and provide a basis for product differentiation (Aaker, 1996). Moreover, brand personalities, like human personalities, are thought to be comprised of traits that are relatively enduring.

Despite a considerable amount of conjecture regarding the consequences associated with developing a strong, positive brand personality, the amount of empirical evidence supporting the premise that brand personality impacts business performance or consumer behavior is negligible. A handful of empirical exceptions suggest that consumers use a brand's personality to express themselves, and that some brand personalities can safeguard a brand against marketplace blunders and enhance brand name transferability to extensions 
in new product categories (Aaker et al., 2004; Aaker, 1999; Batra et al., 1993; Haigood, 1999; Phau and Kong Cheen, 2001). There is a clear need for empirical research that investigates the impact of brand personality on both individual-level (e.g. brand awareness and purchase intent) and product-level (e.g. brand equity and market share) performance measures.

At the individual level, it is possible that brand personality influences consumers' perceptual processing of product information. Information about a brand's personality is not typical sensory information that enables an individual to see, hear, taste, smell, or feel objects (such as a product) in the world. However, most psychophysiologists would concede that one's perceptions have qualities that are not present in the physical attributes of the stimulus (Sekuler and Blake, 1994). Consequently, brand personality can be seen as a nonphysical piece of product knowledge that shapes perceptions about that product. Sekuler and Blake (1994) describe four ways in which knowledge may influence one's perceptions:

(1) By enabling categorization.

(2) By controlling attention.

(3) By guiding acquisition of sensory data.

(4) By supplying context for sensory data.

The third mode is particularly useful for explaining how knowledge about a brand's personality might affect product perceptions. These authors suggest that helpful cues that are intrinsic to the stimulus itself may guide acquisition and processing of subsequent information.

Research in marketing further suggests that a given product has intrinsic and extrinsic cues that have an impact on perceptual processing. Intrinsic cues typically involve the physical composition of a given product. They cannot be changed without altering the nature of the product itself and are consumed as the product is consumed. Returning to the soft drink example, intrinsic cues would include such attributes as flavor, color, texture, and degree of sweetness. Extrinsic cues are product-related but not part of the physical product itself (i.e. they are outside the product). For example, brand name is an extrinsic cue frequently used as a surrogate for intrinsic product attributes and as a proxy for product quality (Jacoby et al., 1978; Jacoby et al., 1977) when the consumer is operating without adequate information about intrinsic product attributes. This situation typically occurs:

- when the consumer has little or no experience with the product;

- when the consumer has insufficient time or interest to evaluate the intrinsic attribute; and

- when the consumer cannot readily evaluate the intrinsic attributes (Zeithaml, 1988). In this light, consumers are also likely to rely on information about a brand's personality as a surrogate for intrinsic product attributes. That is, brand personality may influence product perceptions, especially when evaluating intrinsic product attributes is difficult.

Evaluating intrinsic product attributes is often difficult for product categories in which differences among the intrinsic attributes of competing brands are hard to discern. Thus, in this instance, brand personality may provide the means for making a given brand stand out in the crowd. Stated differently, when intrinsic cues are very similar for competing brands, 
brand personality may create a basis for differentiation. For parity products, then, the presence of claims communicating a strong, positive brand personality (i.e. providing extrinsic and intrinsic cues) should lead to relatively higher product evaluations in comparison to the presence of claims that merely inform consumers about the product's features and benefits (i.e. provide intrinsic cues only). Based on the foregoing discussion, and consistent with prior research expectations, we offer the following main effect prediction:

H1. When subjects are exposed to stimulus material featuring information about the product's features and the product's brand personality (versus stimulus information about the product's features only), their product evaluations will be significantly more favorable. Aside from creating a point of difference for an otherwise indistinct brand via brand attitudes and purchase intentions, favorable extrinsic product information - such as information about the brand's personality - may also increase attention paid to the brand (Sekuler and Blake, 1994) and stimulate active information processing (Biel, 1992). A critical corollary of this cognitive activity is the emergence of more brand associations, especially ones that are favorable in nature (Belk, 1988; Kleine et al., 1993; Malhotra, 1981). This is important, because the number and nature of a given brand's associations are thought to be indicative of its brand equity (Aaker, 1991; Keller, 1993). So, the presence of claims communicating a distinctly positive brand personality should lead to more brand associations relative to when only product information is given. Further, consistent with Keller's (1993) conceptualization of brand equity, resulting brand associations should be more favorable, strong, unique, and congruent than associations that surface after exposure to only product information.

$\mathrm{H} 2$. When subjects are exposed to stimulus materials featuring information about the product's features and the products brand personality (versus stimulus information about the product's features only), they will express: (a) a significantly greater number of total brand associations; (b) a significantly greater proportion of favorable brand associations; (c) a signify greater proportion of unique brand associations; (d) a significantly greater proportion of congruent brand associations; and (e) a significantly greater proportion of strong brand associations.

\section{Method}

Subjects and design

A one-way MANOVA design was used, consisting of six levels of brand personality:

(1) Product information only (i.e. no brand personality).

(2) Product information $\mathrm{p}$ a sincere brand personality.

(3) Product information pa competent brand personality.

(4) Product information $\mathrm{p}$ an excited brand personality.

(5) Product information $\mathrm{p}$ sophisticated brand personality.

(6) Product information $\mathrm{p}$ a rugged brand personality.

A total of 192 students enrolled in an undergraduate marketing course at a large southwestern university participated in the study. For participation each student received extra credit points toward his or her final grade in the course. 


\section{Pretesting}

Several stages of pretesting were necessary to develop stimulus materials and manipulations. For example, one pretest was necessary to identify a product for which subjects had sufficient familiarity and involvement, so that they would be motivated and able to comprehend and process the stimulus materials. A secondary goal of this pretest was to identify a product for which familiarity and involvement levels were fairly homogeneous to present some control for these variables.

This pretest consisted of administering Zaichkowsky's (1994) personal involvement inventory to 50 subjects for 13 different products. Results suggested that bottled water was likely to conform to the established criteria for this subject pool. That is, relative to other products, pretesting indicated that subjects were sufficiently involved (M 1/4 4:4 on a sevenpoint scale) and familiar (M 1/4 6:18 on a seven-point scale) with bottled water, and that variance for both variables (SD 1/4 1:08 and SD 1/4 1:3 for involvement and familiarity, respectively) was also minimal.

A second pretest assessed fictitious brand names for the target product. Based on this pretest, Jatim (pronounced zha“ te'm) was selected as the brand name because, relative to other names in the pretest, it did not carry any strong cognitive or affective associations for bottled water or any other product, so subjects' previous experiences would not interfere with the manipulations.

Based on these two pretests, several vignettes for Jatim bottled water were constructed. The goal was to create six versions of the same vignette that varied in the information presented. All six vignettes contained identical product descriptions that presented information about the basic physical product features (e.g. size, dimensions, quantity, ingredients or constituent elements, and nutritional data). However, each vignette contained a different set of consumer comments about the product. Subjects were told that these consumer comments emerged during focus groups conducted by the company manufacturing Jatim. These consumer comments served as the brand personality manipulation.

The vignette for the fi st treatment (i.e. no brand personality) presented the product description, accompanied by a set of consumer comments reinforcing the product benefit claims, but not communicating any particular brand personality. For example, one such consumer comment was "I drink Jatim because it quenches my thirst." Vignettes for the remaining five treatment conditions presented consumer comments that were purposefully crafted to clearly reflect one particular brand personality dimension of the five dimensions in Aaker's (1997) brand personality scale (BPS). Care was taken to ensure that each vignette had approximately equal amounts of text, to increase the likelihood that responses would be a function of information content rather than information quantity. A panel of expert judges initially examined the vignettes for content validity and the presence of any potential confounds. Finally, using 50 student subjects, the vignettes were pretested to ensure that they were reliably rated as descriptive, realistic, useful, and favorable, and to ensure that no one vignette was significantly different from the others on these criteria. The 
results of this final pretest also revealed that subjects could correctly identify the intended brand personality dimension depicted by the information in the vignettes.

Procedure

The experiment took place in a classroom research setting, wherein subjects were randomly assigned to the six treatment conditions so that each cell contained approximately 30 subjects. Upon entering the experimental room, an experimenter greeted subjects and handed them a booklet containing a description of the study's purpose, basic instructions, the stimulus material, and related measures. To control for demand effects, the questionnaire cover page informed subjects that the experimenters had no association with the manufacturer or the advertising agency for Jatim, and simply desired honest answers. The experimenter specifically instructed subjects not to communicate with or observe the work of others. Further, subjects were spatially separated while completing the questionnaire and did not know that other subjects received different information based on their cell assignment. The experimenter also instructed subjects not to page ahead in the stimulus booklet or go back and change responses.

Following the cover page, subjects read a cover story and a paragraph orienting them to the task. The cover story told subjects that their opinions were being solicited by the manufacturer of a new brand of bottled water to be introduced in the market shortly. Subjects had approximately two minutes to read the description of the study's purpose and the instructions before being instructed them to turn the page. On the next page subjects saw the stimulus vignette for their assigned cell. Directions on this page instructed subjects to take a few minutes to read the information. After reviewing the vignettes, subjects were given three minutes to describe their thoughts about bottled water in general, including any related feelings, expected benefits, or personal experiences. Next, subjects' thoughts about the promoted brand of bottled water specifically were elicited by repeating the exercise for Jatim (since evaluating the uniqueness of brand associations for Jatim requires a comparison to brand associations for bottled water in general, it was necessary to obtain cognitive responses for both).

Following the thought-listing exercises, subjects answered several questions regarding their evaluations of the information and the brand discussed in the vignettes. Measures included attitude toward the brand and purchase intentions. Attitude toward the brand was measured by asking subjects to complete the statement, "I feel Jatim bottled water is ... ." using four seven-point semantic differential items (anchored by favorable ... unfavorable, good ... bad, likable

... unlikable, and pleasant .. . unpleasant). An average of the scales was used to form a brand attitude index. This measure is consistent with those reported in the marketing literature (Edell and Staelin, 1983). Subjects were also asked to indicate the likelihood that they would purchase Jatim bottled water when it became available in local stores using four seven-point semantic differential items (anchored by very likely ... not at all likely, very probably ... not at all probably, very possible ... not at all possible, and very certain .. . not at all certain). This measure of purchase intention parallels those used in previous 
studies (Bennett and Harrell, 1975; Dover and Olson, 1977; Smith and Swinyard, 1983; MacKenzie, 1986; Marks and Kamins, 1988).

Following the measures of attitude toward the brand and purchase intention, subjects responded to several manipulation checks. First, subjects indicated, using a seven-point scale (anchored by to a great extent ... not at all), the extent to which Jatim possessed a personality. Then, subjects indicated, using a seven-point scale (anchored by extremely ... not at all) how Jatim rated on each of the BPS personality dimensions and how important they felt it was for a brand of bottled water to possess each of these personality dimensions. Finally, subjects indicated which one brand personality dimension best reflected Jatim's personality, to ensure that the intended dimension had been effectively manipulated.

Covariates

Extant research suggests several individual-level constructs can affect consumers' processing of advertising claims. These include product familiarity, which could affect:

- $\quad$ motivation to process advertising claims (Wright, 1975);

- the handling of inconsistent information;

- attention to information that is important to choice (Johnson and Russo, 1984); and - $\quad$ cognitive elaboration (Marks and Olson, 1981).

In addition to familiarity, product involvement can also influence the manner in which subjects process information about brand personality. For example, product involvement could affect attention to ads (Greenwald and Leavitt, 1984; Celsi and Olson, 1988), cognitive effort during the comprehension of ads (Woodside, 1983), elaboration of product-related aspects of ads (Batra, 1985), and brand recall (Petty et al., 1983; Gardner, 1983; Gardner et al., 1985; Leigh and Menon, 1987; Mitchell, 1980; Nelson et al., 1985). Controlling for individual differences in product knowledge consisted of measuring familiarity by having subjects respond to two items:

(1) "Compared to most people, how familiar are you with bottled water?" (seven-point scale anchored by "not at all familiar" and "extremely familiar").

(2) "Please indicate how frequently you have bought bottled water within the last month" (seven-point scale anchored by "not at all" and "very frequently").

These scales were combined to form the product familiarity index. This measure is consistent with those used in previous studies (Darley and Smith, 1993). To control for individual differences in product involvement, Zaichkowsky's (1994) personal involvement inventory was included in the questionnaire for use as a potential covariate. The items in this scale were combined to form the product involvement index.

Delayed measures

Assessing brand association strength necessitated measuring the degree to which Jatim's brand name was memorable and brand associations were enduring. Hence, subjects answered a few follow-up questions in a brief, subsequent research session that took place one week after the initial experiment. They first responded to an unaided recall question that asked them to provide the brand name of the bottled water they had previously evaluated. Then, they were again given three minutes to record their thoughts about Jatim 
bottled water. The accuracy of responses to the memory question and consistency of cognitive responses across measurement times were used to measure the strength of respondents' brand associations.

An open-ended item at the end of the second questionnaire asked subjects to guess the purpose of the study. Examination of these remarks indicated that subjects accepted the experimental guise and none guessed the true purpose of the study. Upon completion of the questionnaire, subjects were debriefed and dismissed.

Coding scheme for cognitive responses

Two raters categorized the written statements obtained in the three thought-listing tasks. Inter-rater agreement was high (98 percent) and discrepancies were resolved through discussion. To simplify discussion, the separate tasks are henceforth referred to as task A (thought-listing for bottled water), task B (first thought-listing for Jatim), and task C (second thought- listing for Jatim).

Raters initially counted all independent statements expressed in task B and task C, and then categorized them by their valence (i.e. expressing positive, neutral, or negative evaluations of the brand). Next, the statements generated by each respondent for task B were categorized according to the overall congruency of their content (i.e. expressing mostly congruent versus mostly incongruent brand associations). Raters then compared the content of statements given for task A and task B in terms of their similarity (i.e. expressing mostly similar versus mostly different brand associations) so that the uniqueness of brand associations in the presence/absence of brand personality information could be gauged. Finally, in order to assess the strength of brand associations given different brand personality manipulations, the content of statements expressed for task B and task $\mathrm{C}$ were categorized in terms of their consistency across time (i.e. expressing brand associations consistent versus inconsistent in meaning). Raters also evaluated the brand name subjects gave in task $\mathrm{C}$ for accuracy (i.e. accurate versus inaccurate).

\section{Results}

Manipulation checks

A one-way ANOVA performed on responses to an item designed to check the extent to which Jatim possessed a brand personality indicated the manipulations operated in the intended manner. Subjects in the no brand personality condition (M 1/4 1:41) rated Jatim's brand personality significantly lower in terms of strength than subjects in the fi e conditions for which a specific brand personality dimension was manipulated (sincerity M 1/4 6:29, competence $M 1 / 4$ 6:64, excitement $M 1 / 4$ 6:80, sophistication $M 1 / 46: 61$, ruggedness $\quad M$ 1/4 6:45) (Fð5;186P 1/4 313:01, p , 0:025). Further, cross tabulations for responses to an item for which subjects indicated the personality trait most reflected in the information presented in the stimulus material indicated specific brand personality dimensions were successfully manipulated. For each of the six treatment conditions, a majority of subjects chose the appropriate brand personality dimension for the manipulation to which they were exposed. Proportions of correct responses ranged from 84.4 percent for the no brand personality condition, to 100 percent for the excitement condition. Taken together the 
results of these manipulation checks provide evidence that brand personality was successfully manipulated.

Interestingly, while most subjects (regardless of their treatment condition) could properly classify Jatim's brand personality by its predominant dimension, an examination of strength ratings for individual brand personality dimensions revealed that in each case Jatim's brand personality was perceived as being comprised of more than one personality dimension, beyond the individual dimension it was intended to reflect. Across conditions, subjects rated Jatim as being competent ( $\mathrm{M}$ 1/4 4:15), second in strength only to the manipulated brand personality dimension in each instance. Jatim was rated lower on each other brand personality dimensions, except for when that dimension was experimentally manipulated (sincerity M 1/4 2:67, excitement M 1/4 2:62, sophistication M 1/4 2:67, ruggedness $M$ 1/4 2:29). Interestingly, subjects also rated competence (M 1/4 4:70) as the dimension they perceived as being most important in a brand of bottled water, regardless of treatment condition (sincerity M $1 / 4$ 4:03, excitement $\quad$ M $1 / 43: 11$, sophistication $M 1 / 4$ 3:30, ruggedness $\mathrm{M} 1 / 4$ 3:42).

\section{Covariates}

Both familiarity and involvement appeared to be appropriate covariates, based on homogeneity tests. However, a correlation analysis performed with the three dependent variables and the two potential covariates indicated that neither familiarity nor involvement had a significant impact on product or information evaluations for Jatim. Familiarity had a low correlation with brand attitudes ( $\mathrm{r} 1 / 4$ 0:020, $\mathrm{p}$. 0:05) purchase intentions $(\mathrm{r} 1 / 4$ 0:009, $\mathrm{p}$ . 0.05). Similarly, involvement had a low correlation with brand attitudes ( $\mathrm{r} 1 / 4$ 0:166, $\mathrm{p}$. 0:05) and purchase intentions ( $1 / 4$ 0:130, p . 0:05). Moreover, separate one-way ANOVAs conducted to assess the relative impact of these potential covariates on individual treatment cells indicated that both familiarity and involvement (Fs , 1:00) had a statistically nonsignificantly on the dependent variables across cells. Given the failure of familiarity and involvement to impact the dependent variables, both covariates were excluded from further analyses.

\section{Brand evaluations}

Support for $\mathrm{H} 1$ required a significant brand personality main effect with all five treatment conditions manipulating a specific brand personality dimension outperforming the no brand personality condition in terms of brand attitudes and purchase intentions. Consistent with $\mathrm{H} 1$, there was a significant main effect with means in the predicted direction (Fð1;190P 1/4 43:557, p , 0:025). These results suggest that subjects exposed to stimulus materials containing information about the brand's personality - regardless of the dimension - had significantly more favorable brand attitudes (sincerity M $1 / 4$ 6:13, competence M $1 / 4$ 6:08, excitement M $1 / 4$ 5:98, sophistication $M 1 / 46: 03$, ruggedness $M 1 / 4$ $5: 84)$ than subjects exposed to stimulus materials containing no information about the brand personality (M 1/4 2:99). Similarly, subjects in treatment conditions for which a specific brand personality dimension was experimentally manipulated had significantly higher purchase intentions (sincerity $M \frac{1}{4}$ 5:55, competence $M \frac{1}{4}$ 5:55, excitement $M \frac{1}{4} 4$ 
5:73, sophistication $M \frac{1}{4}$ 5:79, ruggedness $M \frac{1}{4}$ 5:72) than subjects in the no brand personality treatment condition (M 1/4 2:38).

Cognitive responses

To provide additional insight into the cognitive basis for subjects' brand evaluations and purchase intentions, a series of ANOVAs on the number and nature of cognitive responses was conducted. While the data were transformed using the recommended arcsine transformation, raw percentages are reported here to simplify discussion.

An ANOVA conducted on the number of cognitive responses generated following exposure to stimulus materials yielded a significant main effect for the Brand Personality manipulation (Fð1;190P 1/4 14:39, p , 0:025). Subjects in the no brand personality condition (M 1/4 0:32) reported significantly fewer brand associations than subjects in the five conditions for which a brand personality dimension was manipulated (sincerity $\mathrm{M} 1 / 43: 86$, competence $M \frac{1}{1} 4: 11$, excitement $M \frac{1}{1} 4$ 3:93, sophistication $M 1 / 4$ 4:04, ruggedness $M \frac{1}{1} 4$ 3:79), supporting H2a.

An examination of the content of cognitive responses generated by subjects exposed to stimulus materials containing information about the brand's personality (i.e. the BPpresent conditions) - regardless of the dimension - versus those exposed to stimulus materials containing no information about the brand personality (i.e. the BP-absent condition) provided further support for expectations regarding brand associations and evidence of the benefits which are thought to be associated with developing a strong, positive brand personality. More specifically, a series of ANOVAs conducted on the proportion of total cognitive responses in terms of valence, consistency, uniqueness, and strength revealed significant differences for the BP-present versus BP-absent treatment conditions.

As predicted by $\mathrm{H} 2 \mathrm{~b}$, compared to BP-absent subjects (56.72 percent), BP-present subjects (83.01 percent) generated a significantly greater proportion of positive cognitive responses (Fð1;190P 1/4 45:62, p, 0:025). Subjects who received information about Jatim's personality were overwhelmingly favorable toward the brand, while those who received only product information seemed more skeptical about the brand and saw it as indistinguishable from other brands of bottled water.

\section{Discussion}

The results of this study provide support for the research hypothesis that stimulus material containing information about a product's physical attributes and its brand personality is associated with higher brand attitudes and purchase intentions. A strong, positive brand personality also leads to more brand associations that are favorable unique, strong, and congruent - thus enhancing brand equity. This effect (i.e. the BP effect) occurred regardless of which brand personality dimension was experimentally manipulated, suggesting that any brand personality, so long as it is perceived as being strong and favorable, is likely to be associated with positive consequences. Further, for product categories (like bottled water) where it is hard to distinguish competing products from one another by their attributes, a strong, positive brand personality may provide a basis for differentiation and a means for influencing consumer perceptions and preferences. Beyond the demonstration that a BP effect exists, this research has two other notable findings. First, 
subjects in this study perceived brand personalities as multifaceted like human personalities, even when only one distinct brand personality dimension was being manipulated. For instance, some subjects exposed to the ruggedness manipulation regarded Jatim's brand personality as being predominantly rugged, with traces of the excitement dimension. While no undesirable personality traits were assessed in the present study, it is also possible that some manipulations could have been regarded as possessing negative dimensions. Given brand personality's capacity to impact product evaluations, marketers must be mindful of the potential for consumers to derive unintended negative conclusions about the brand's personality from marketing communications.

Secondly, it is interesting to note that regardless of the treatment condition, competence consistently received the highest importance ratings. This finding may be explained using the concept of the determinant attribute, which holds that the most important attributes are often not the ones that distinguish competing brands from one another. Lovelock (1984) provides the following example:

Most travelers rank "safety" as their number one consideration for air travel. But since major US airlines are generally perceived as equally safe, safety is not usually any attribute that influences consumer choice between several major domestic carriers (p. 100).

Determinant attributes (i.e. those that do determine choice) may be low on a list of priorities, but they are often the attributes that demarcate competing alternatives from one another (Lovelock, 1984, p. 102). So, for products like bottled water, which are perceived as being equally competent, other brand personality dimensions may be more effective in terms of differentiation. To illustrate, sophistication was perceived as being relatively less important than competence in the present study, but was associated with relatively higher purchase intentions.

\section{Conclusions}

\section{Contributions}

In this research an attempt was made to conceptually clarify the domain of the brand personality construct, and to disentangle brand personality from other related constructs such as brand identity and brand image. Brand personality was conceptualized here as one of many associations comprising brand image, which in turn is a subset of brand identity. Additionally, research on associative memory formulation was utilized to explain how brand personality operates. That is, brand personality was conceptualized as one type of brand association in consumer memory that may be accessed as the need or desire for a particular product arises, and that may influence consumer preferences.

Finally, this research empirically tested the BP effect. The key finding emerging from this study is that, after controlling for familiarity and involvement, a strong, favorable brand personality is related to more favorable product evaluations and brand associations - that suggests that developing a distinctly positive personality for a brand may enrich its brand equity. This finding is entirely consistent with the intuition and expectations of both scholars and practitioners about the nature and effects of brand personality, and provides a 
basis (beyond mere intuition and anecdotal evidence) for endorsing efforts to develop a strong, favorable brand personality. This research has clear implications for practitioners, namely that a product that is largely indistinct (in terms of its physical attributes) may be set apart from competing brands through the development of a strong, favorable brand personality. Since a brand personality that is perceived in a like manner by a group of target consumers is thought to be difficult to create and relatively enduring, brand personality may also offer a distinct form of sustainable competitive advantage.

Limitations and future research

Although it adds to our understanding of brand personality, this research has limitations that may be pursued in future research. Many of the caveats typically associated with laboratory research apply to the present study as well. Conclusions concerning the BP effect are most applicable to this research setting, target product, and student population. With respect to the research setting, it is important to note that most of the data was collected at a single point in time, following exposure to a single set of stimulus material. Although even this single exposure produced a BP effect, it is necessary to investigate the effects of long-term, repeated exposures to such information. Another important caveat relating to the research setting is the fact that respondents participated in an environment that may have caused them to engage in a more extensive evaluation of the stimulus material than would be the case in a natural ad-processing situation. Unlike the typical advertising exposure situation, all subjects were asked to form brand evaluations at the time of exposure to stimulus material. It is possible that this forced exposure and evaluation increased subjects' interest in the material and enhanced their responsiveness to brand personality manipulations, primarily because respondents knew their responses were being recorded and examined. These observations suggest the need to consider the extent to which the brand personality effect generalizes to different settings, and with different time frames and exposures.

The student population used in this study also deserves mention. Admittedly, this is a homogeneous group that presumably has greater than average cognitive capabilities. Hence, there is an obvious need to replicate this study using samples with different demographic profit to extend generalizability of results.

In regard to the target product studied, this study only examined one product category, bottled water. This stimulus product was chosen because of its relevance to student subjects and the relative physical similarity among brands; however, an important question for further research would focus on the extent to which the findings would generalize to other

product categories. This suggests a need to replicate this study using diverse products to increase confidence in these findings.

\section{References}

1. Debasis Pradhan, Israel Duraipandian, Dhruv Sethi. 2016. Celebrity endorsement: How celebrity-brand-user personality congruence affects brand attitude and purchase intention. Journal of Marketing Communications 22:5, 456-473. [CrossRef]

2. Richard Rutter, Fiona Lettice, John Nadeau. 2016. Brand personality in higher education: anthropomorphized 
university marketing communications. Journal of Marketing for Higher Education 1-21. [CrossRef]

3. Hany Kim, Svetlana Stepchenkova. 2016. Understanding destination personality through visitors' experience: A cross-cultural perspective. Journal of Destination Marketing \& Management . [CrossRef]

4. Jin Su Department of Human Development and Environmental Studies, Indiana University of Pennsylvania, Indiana, Pennsylvania, USA . 2016. Examining the relationships among the brand equity dimensions. Asia Pacific Journal of Marketing and Logistics 28:3, 464-480. [Abstract] [Full Text] [PDF]

5. Jin Su, Xiao Tong. 2016. Brand Personality, Consumer Satisfaction, and Loyalty: A Perspective from Denim Jeans Brands.

Family and Consumer Sciences Research Journal 44:4, 427-446. [CrossRef]

6. Azwardi Md Isa, Mohammad Basir Saud, Md Daud Ismail. 2016. Examining reasons for post-purchase satisfaction in buying localbrands: When local meets local.Asia Pacific Management Review 21:1,48-61.[CrossRef]

7. Zhihong Liu, Songshan (Sam) Huang, Rob Hallak, Mingzhu Liang. 2016. Chinese consumers' brand personality perceptions of tourism real estate firms. Tourism Management 52, 310-326. [CrossRef]

8. Aditya S. Mishra, Subhadip Roy, Ainsworth Anthony Bailey. 2015. Exploring Brand Personality-Celebrity Endorser Personality Congruence in Celebrity Endorsements in the Indian Context. Psychology \& Marketing 32:12, 11581174. [CrossRef]

9. Arpita Khare. 2015. Influence of green self-identity, past environmental behaviour and income on Indian consumers' environmentally friendly behaviour. Journal of Global Scholars of Marketing Science 25:4, 379-395. [CrossRef]

10. Saeed Shobeiri, Ebrahim Mazaheri, Michel Laroche. 2015. How Would the E-Retailer's Website Personality Impact Customers' Attitudes toward the Site?.Journal of Marketing Theory and Practice 23:4, 388-401. [CrossRef]

11. Muhammad Ahmed Department of Business Administration, International Islamic University Malaysia, Kuala Lumpur, Malaysia Muhammad Tahir Jan Department of Business Administration, International Islamic University Malaysia, Kuala Lumpur, Malaysia . 2015. An extension of Aaker's brand personality model from Islamic perspective: a conceptual study. Journal of Islamic Marketing 6:3, 388-405. [Abstract] [Full Text] [PDF]

12. Mark S. Glynn, Tiza Widjaja. 2015. Private label personality: applying brand personality to private label brands. The International Review of Retail, Distribution and Consumer Research 25:4, 362-378. [CrossRef]

13. Syed Zamberi Ahmad, Frederick Robert Buchanan. 2015. Motivation factors in students decision to study at international branch campuses in Malaysia. Studies in Higher Education 1-18. [CrossRef]

14. Darren Andrew Coleman Wavelength Marketing, Birmingham, UK Leslie de Chernatony Aston Business School, Aston University, Birmingham, UK George Christodoulides Department of Management, Birkbeck, University of London, London, UK . 2015. B2B service brand identity and brand performance. European Journal of Marketing 49:7/8, 1139-1162. [Abstract] [Full Text] [PDF]

15. Sunghun Chung, Jooyoung Park. 2015. The influence of brand personality and relative brand identification on brand loyalty in the European mobile phone market. Canadian Journal of Administrative Sciences / Revue Canadienne des Sciences de l'Administration n/a-n/a. [CrossRef]

16. Jin Su Department of Human Development and Environmental Studies, Indiana University of Pennsylvania, Indiana, Pennsylvania, USA Xiao Tong Department of Clothing, Textiles and Interior Design, The University of Alabama, Tuscaloosa, Alabama, USA . 2015. Brand personality and brand equity: evidence from the sportswear industry. Journal of Product \& Brand Management 24:2, 124-133. [Abstract] [Full Text] [PDF]

17. Sascha Steinmann, Gunnar Mau, Hanna Schramm-Klein. 2015. Brand Communication Success in Online Consumption Communities: An Experimental Analysis of the Effects of Communication Style and Brand Pictorial Representation. Psychology \& Marketing 32:3, 356-371. [CrossRef]

18. Leslie de ChernatonyBrand Personality 1-1. [CrossRef]

19. Kojo Mensah Sedzro, Godfred Amewu, Joseph Darko, Ezekiel Nii Noye Nortey, Julius B. Dasah. 2014. Determinants of Automobile Purchase and Brand Choice in Ghana: Multinomial Logit Approach. Journal of Transnational Management 19:4, 303-317. [CrossRef] 
20. Xiao Tong Department of Clothing, Textiles, and Interior Design, The University of Alabama, Tuscaloosa, Alabama, USA Jin Su Department of Human Development and Environmental Studies, Indiana University of Pennsylvania, Indiana, Pennsylvania,USA . 2014. Exploring the personality of sportswear brands. Sport, Business and Management: An International Journal 4:2, 178-192. [Abstract] [Full Text] [PDF]

21. Carolin Plewa Senior Lecturer Marketing, University of Adelaide Business School, University of Adelaide,10 Pulteney Street, Adelaide, SA 5005, Australia Karen Palmer Marketing and Sales Manager, Stratford Arts Trust, UK; paper completed while a student at University of Adelaide Business School . 2014. Self-congruence theory: towards a greater understanding of the global and malleable selves in a sports specific consumption context. International Journal of Sports Marketing and Sponsorship 15:4, 26-39. [Abstract] [PDF]

22. Cigdem Basfirinci Karadeniz Technical University, Trabzon, Turkey . 2013. Effect of brand origin on brand personality perceptions: an empirical analysis from Turkey. Asia Pacific Journal of Marketing and Logistics 25:4, 539-560. [Abstract] [Full Text] [PDF]

23. Minkyung Choy, Jae II Kim. 2013. New brands diluting the personality of existing brands. Journal of Brand Management 20:7, 590-607. [CrossRef]

24. Ching-Fu Chen, Sambath Phou. 2013. A closer look at destination: Image, personality, relationship and loyalty. Tourism Management36,269-278. [CrossRef]

25. Collin R. Payne, Michael R. Hyman, Mihai Niculescu, Bruce A. Huhmann. 2013. Anthropomorphic responses to new-to-market logos. JournalofMarketing Management 29:1-2,122-140. [CrossRef]

26. Saeed Shobeiri, Michel Laroche, Ebrahim Mazaheri. 2013. Shaping e-retailer's website personality: The importance of experiential marketing. Journal of Retailing and Consumer Services 20:1, 102-110. [CrossRef]

27. Gareth Haarhoff, Nicola Kleyn. 2012. Open source brands and their online brand personality. Journal of Brand Management

20:2, 104-114. [CrossRef]

28. Bedman NartehDepartment of Marketing, University of Ghana Business School, Accra, Ghana Raphael OdoomDepartment of Marketing, University of Ghana Business School, Accra, Ghana Mahama BraimahDepartment of Marketing, University of Ghana Business School, Accra, Ghana Samuel BuameDepartment of Marketing, University of Ghana Business School, Accra, Ghana. 2012. Key drivers of automobile brand choice in sub-Saharan Africa: the case of Ghana. Journal of Product \& Brand Management 21:7, 516-528. [Abstract] [Full Text] [PDF]

29. Kim Willems, Wim Janssens, Gilbert Swinnen, Malaika Brengman, Sandra Streukens, Mark Vancauteren. 2012. From Armani toZara: Impression formation based on fashion store patronage. Journal of Business Research 65:10, 1487-1494. [CrossRef]

30. Lauren I. Labrecque, George R. Milne. 2012. Exciting red and competent blue: the importance of color in marketing. Journal of the Academy of Marketing Science 40:5, 711-727. [CrossRef]

31. Amir Ekhlassi, Majid Hassani Nezhad, Siamak Ashkan Far, Kamal Rahmani. 2012. The relationship between brand personality and customer personality, gender and income: A case study of the cell phone market in Iran. Journal of Targeting, Measurement and Analysis for Marketing 20:3-4, 158-171. [CrossRef]

32. Fethi Klabi. 2012. The predictive power of destination-personality-congruity on tourist preference: a global approach to destination image branding. Leisure/Loisir 36:3-4,309-331. [CrossRef]

33. Rodoula TsiotsouDepartment of Marketing and Operations Management, University of Macedonia, Edessa, Greece. 2012. Developing a scale for measuring the personality of sport teams. Journal of Services Marketing 26:4, 238-252. [Abstract] [Full Text] [PDF]

34. Hazel H. Huang, Vincent-Wayne Mitchell, Richard Rosenaum-Elliott. 2012. Are Consumer and Brand Personalities the Same?.

Psychology \& Marketing 29:5, 334-349. [CrossRef]

35. Richard R. Klink, Gerard A. Athaide. 2012. Creating brand personality with brand names. Marketing Letters 23:1, 109-117. [CrossRef]

36. Mark Avis. 2012. Brand personality factor based models: A critical review. Australasian Marketing Journal (AMJ) 20:1, 89-96. [CrossRef] 